\title{
UM MARCO CONCEITUAL AO TRABALHO DA ENFERMAGEM NA CENTRAL DE MATERIAL E ESTERILIZAÇÃO*
}

[A conceptual landmark of the nursing work process at the center of material and sterilization] [U n mojón conceptual al proceso de trabajo de enfermería en la central de material y esterilización]

Samanta A ndrine M arschall Taube** Ivete Palmira Sanson Zagonel*** $M$ arineli J oaquim M éier****

RESUMO: A Central de M aterial e Esterilização (CM E) é um setor de serviços de saúde que possui saberes e práticas específicos ao seu processo de trabalho, e são passíveis de reflexões que podem ser realizadas por meio do estudo das teorias de enfermagem, de seus conceitos (percepções, definições) e proposições (deduções, propostas), formando um marco conceitual. Esta reflexão teórica tem por objetivos compreender os conceitos que envolvem o processo de trabalho da enfermagem na CME. A pós a apropriação e discussão pelas autoras dos conceitos que formam 0 metaparadigma da enfermagem, ser humano, ambiente, processo saúde-doença e enfermagem, foi possível a reflexão de conceitos que podem ser adaptados à prática da CM E e se tornarem uma 'ferramenta' para entender a importância de seu trabalho e subsidiar a prática da enfermagem na área.

PALAVRAS-CHAVE: Trabalho; Enfermagem; Prática profissional; Central de M aterial e Esterilização; Teoria de enfermagem.

\section{IINTRODUÇÃO}

As ações vivenciadas no dia-a-dia do processo de

\footnotetext{
*Trabalho resultante da Disciplina Concepções Teórico-Filosóficas e M etodológicas da Prática Profissional do Curso de M estrado em Enfermagem da UFPR.

**Enfermeira. Bolsista da CA PES/ M estrado do Programa de Pósgraduação. M embro do Grupo de Estudos M ultiprofissional em Saúde do A dulto - GEM SA - do Departamento de Enfermagem da UFPR. ***Enfermeira. Doutora em Enfermagem, Professora Sênior do Programa de Pós-Graduação em Enfermagem da UFPR. Coordenadora do Núcleo de Estudos, Pesquisa e Extensão em Cuidado Humano de Enfermagem - NEPECHE/UFPR. Coordenadora do Curso de Enfermagem do IESPP.

****Enfermeira. Doutora em Filosofia de Enfermagem. Professora do Programa de Pós-Graduação em Enfermagem da UFPR. M embro do GEMSA .
}

trabalho da Enfermagem são passíveis de reflexões que conduzem ao (re) pensar da sua prática, em um exercício envolvente que faz emergir sentimentos e lembranças do "jeito" de fazer a profissão. Neste exercício de reflexão, pode ser utilizada a analogia de uma gravação de imagens por meio de uma câmera de vídeo, que resultará em uma filmagem para ser assistida quando for necessário. Rel embrar é como retroceder e assistir a um filme para rever detal hes despercebidos dos momentos vividos na prática e, também, auxiliar a elaboração de novos momentos emaneira de se processar o trabal ho (filmes), de um "jeito" diferente, amadurecido.

Construir novos filmes significa acompanhar as mudanças históricas, políticas e sociais e as demandas de saúde, com a criação de modelos, metodologias e teorias que possam instrumentalizar as práticas da enfermagem. As teorias podem ser consideradas imagens que refletem realidades da profissão, sem se constituir em miragens ou frutos da imaginação de quem as escrevem, por possuírem uma estrutura composta de el ementos estruturais e funcionais que direcionam, delimitam e explicam sua operacionalidade. Dentre estes, encontram-se os conceitos e as proposições ${ }^{(1,2)}$.

Conceitos podem ser definidos como idéias, percepções, abstrações de um fenômeno/ acontecimento, imagens mentais ou símbol os das palavras que podem guiar e fazer compreender as observações do mundo ${ }^{(2,3)}$. Eles correspondem à "idéia, objeto concebido pelo espírito ou adquirido por el e e que permite organizar as percepções e os conhecimentos" (4:214). Em relação às proposições, são consideradas como "[...] a inter-relação de conceitos que evidencia a proposta de explicação sobre um fato ou fenômeno" (2:51). Correspondem à ação de propor, de submeter ao exame, como deduções, induções, direções à evolução e aplicabilidade de uma teoria, pois descrevem, explicam e predizem fenômenos ${ }^{(2,4)}$.

J untos, os conceitos e proposições formam o marco conceitual, que direciona as ações da enfermagem e pode ser representado por uma "câmera", pela qual se pode olhar, 
filmar e se aproximar de realidades. Esta "câmera" (marco conceitual) direciona a construção (reflexão/ação) e gravação (conhecimento, pesquisa, publicações) de novos filmes (práticas, saberes). Pensa-se que o marco conceitual é uma importante "ferramenta" de representação e identificação das características do saber/fazer de uma profissão que possibilita construir conhecimento científico por meio da reflexão dos conceitos que circundam seu processo de trabalho ${ }^{(5)}$.

Entende-se por processo de trabal ho, as ações que envolvem o homem e a natureza, pois o homem apropriase dos recursos da natureza, atua sobre ela, modifica-a e modifica a si mesmo ${ }^{(6)}$. $\mathrm{Na}$ Enfermagem, percebe-se que ele faz parte do trabalho da saúde e é composto por um conjunto de elementos (objeto, instrumentos e finalidade) que envolve pessoas e dimensões práticas (o cuidar, o educar e 0 gerenciar) que caracterizam o saber/fazer da profissão $(7,8,9)$. Este processo pode ser desenvolvido em diferentes setores das instituições e serviços de saúde, e um del es éo da Central de M aterial e Esterilização (CM E).

A CME possui uma historicidade e dinamicidade em suas práticas e saberes e, por isso, torna-se importante comentar a sua trajetória. A história da CM E revela que suas ações vêm acompanhando as necessidades dos procedimentos cirúrgicos, no intuito de controlar as infecções no pós-operatório e melhorar as condições da cirurgia. Para acompanhar tais necessidades, apropriou-se de teorias, modelos, sistematizações e conhecimentos para direcionar suas práticas, dentre os quais pode ser observada a presença de um marco conceitual que envolve os conceitos de ser humano, ambiente, processo saúde/doença e Enfermagem, adaptados à realidade do setor.

M ediante essas informações, a abordagem da temática se justifica no desejo de compreender os conceitos que envolvem o processo de trabal ho da Enfermagem na CM E, pela importância pessoal atribuída às ações realizadas neste setor, fato que instigou reflexões. Somado a isso, a disciplina de Concepções Teórico-filosóficas e $M$ etodológicas para a Prática Profissional em Enfermagem, do curso de M estrado da Universidade Federal do Paraná (UFPR), proporcionou o contato e estudo dos conceitos que compõem o metaparadigma da Enfermagem, das teorias e do marco conceitual da enfermagem. A credita-se que ao trabal har embasado em um marco conceitual, o enfermeiro possa refletir a respeito da sua prática, à medida que direciona o pensamento à investigação e à ação ${ }^{(10)}$.

Para a construção deste artigo, optou-se por abordar um breve histórico da CME e a inserção da Enfermagem nesse setor, o seu processo de trabalho e as relações, conceitos e proposições que o envolvem. Como referencial teórico adotou-se o processo de trabalho em Enfermagem, com a articulação dos conceitos que o compõem, os quais estão inseridos no contexto particular da Central de M aterial e Esterilização. Processo de trabalho, por determinar sistematização às ações de cuidar, que auxilia para definir a qualidade e a ordem de tais ações em uma estrutura conceitual com fundamentação científica. A ssim, objetiva compreender os conceitos que envolvem o processo de trabalho da Enfermagem na Central de Material e Esterilização (CME) e propor um marco conceitual para esta área, embasado nos conceitos que formam o metaparadigma da profissão (ser humano, ambiente, processo saúde-doença e enfermagem), a partir da vivência profissional da autora e do estudo de autores que abordam as temáticas envolvidas.

\section{CONTEXTUALIZAÇÃO DA ENFERMAGEM NA CENTRAL DE MATERIAL E ESTERILIZAÇÃO: SUAS CÂMERAS, SEUS FILMES}

U ma breve retrospectiva histórica da Central de $M$ aterial e Esterilização (CM E) vincula seu surgimento ao das cirurgias no início do século XIX, as quais eram tidas como última al ternativa de intervenção à doença, devido à presença de "inimigos mortais" como a febre do pósoperatório, resultado de precárias condições de higiene, assepsia, recursos e conhecimentos. Um dos fatores predisponentes às infecções, após a cirurgia, referia-se à falta de limpeza dos materiais ou, quando limpos, a limpeza era realizada de qualquer maneira, em aventais e trapos, sendo igual mente guardados de modo precário $(11,12,13,14)$.

Por consequêencia da fal ta de higiene e de recursos, muitos cirurgiões perderam a esperança no sucesso da cirurgia, pelo quadro de febre, dor e morte que se via em todos os cantos do mundo. $M$ as, a persistência de alguns cirurgiões, não convencidos da invencibilidade das infecções, resultou em descobertas realizadas nas salas operatórias. Inácio Filipe Semmelweis (1818-1865) preconizou a lavagem das mãos, J oseph L ister (1827-1912) iniciou tratamentos anti-sépticos em feridas, instrumentos cirúrgicos e vaporizadores e Robert Koch (1843-1910) descobriu bactérias e inventou um meio bactericida (vapor de água em ebulição) que exterminava bactérias por meio de um jato de vapor de água fervente, uma idéia que mais tarde, criou a esterilização por vapor de água ${ }^{(12,14)}$. Neste ínterim de descobertas da M edicina, surgiram as práticas da enfermeira Florence Nightingale (1820-1910), que se preocupou com as condições de higiene dos ambientes hospitalares e dos materiais utilizados para o cuidado aos doentes.

A liadas a essas descobertas, a ocorrência das infecções e epidemias na população e a necessidade de medidas de saúde pública levaram o governo a reestruturar os hospitais, o que se consolidou com o avanço da tecnologia e da medicina proporcionado pela Revolução Industrial. Essas medidas influenciaram o desenvolvimento da cirurgia, as técnicas assépticas, a criação de novos instrumentos e materiais cirúrgicos e 0 aumento do cuidado com sua limpeza e esterilização. A partir daí, houve a necessidade de um local específico para mani pulação dos materiais após 
a cirurgia, o que fez surgir a CME.

Inicial mente, a CM E foi anexada às salas operatórias e as áreas de preparo dos materiais ficavam nas unidades de internação, conforme as especialidades médicas. Com 0 avanço das técnicas operatórias, da especificidade dos instrumentais e da necessi dade de pessoal em quantidade e qualidade para lidarem com eles, o espaço da CME foi centralizado concomitante à centralização das salas de cirurgia (Centro Cirúrgico) para otimizar, racionalizar e facilitar o trabalho às cirurgias ${ }^{(11,13,15,16)}$.

A tualmente, a CM E apresenta uma estrutura física de diferentes formatos, podendo estar agregada ao setor de Centro Cirúrgico, descentralizada como setor independente em instituições de saúde, integrada às clínicas dos cursos de saúde nas instituições de ensino que realizam atendimento de saúde e, ainda, como empresa de serviços de esterilização, independente das instituições de saúde. No que se refere à sua apresentação, al guns autores apontam a necessidade de um espaço independente e autônomo, pelo aparato tecnológico que a configurou, pelo avanço de conhecimentos na área e por atender variados setores de saúde ${ }^{(11,18)}$.

Os avanços da cirurgia e a necessi dade de controlar infecções fazem com que a CM E seja vista como um local de importância à qualidade da prestação de serviços hospitalares, pela necessidade de qualificação, de pesquisas e de integração com as unidades consumidoras, as quais prestam serviços de prevenção, de diagnose e de terapêutica aos seus clientes ${ }^{(11,16,17)}$

Escrever a respeito da história da CM E possibilita refletir sobre conhecimentos e ações do seu processo de trabalho, sobre a inserção da Enfermagem nessa área e sobre os 'porquês' de sua configuração atual. É como retroceder um filme e assistir a cada detalhe e, em seguida, poder refletir e encontrar respostas e caminhos aos problemas vividos na prática. Percebe-se que a trajetória histórica da CME formou um processo de trabalho indispensável à cirurgia, pois envolveu um conjunto de práticas e de recursos físicos, materiais e humanos ao processamento de materiais cirúrgicos.

Durante o percurso da organização da CME, a Enfermagem foi inserida em seu funcionamento e formou uma equipe composta de técnicos e auxiliares de enfermagem e 0 enfermeiro. Os dois primeiros realizam atividades diversas com materiais e o terceiro é 0 profissional habilitado para responsabilizar-se da coordenação desse setor. E sta equipe passou a desenvolver um processo de trabalho que responde às atividades de limpeza, preparo, acondicionamento, desinfecção, esterilização, armazenamento e distribuição de materiais odonto-médico-hospitalares a diferentes setores e serviços de saúde ${ }^{(11,18)}$

Entende-se como processo de trabalho o conjunto de atividades complementares e interdependentes ao processo de saúde, constituído por objeto, instrumentos, finalidade, e que envolve pessoas e dimensões práticas (o cuidar, o educar e o gerenciar) que caracterizam e transformam o ser, o saber e o fazer da profissão. Como objeto de trabalho da Enfermagem está o cuidado ao cliente; como instrumentos podem ser citados o processo de Enfermagem, o cuidado, as técnicas, os materiais e equipamentos, a comunicação, orientação e interação, conhecimento científico e sistematizado, dentre outros (considerados como tecnologias de enfermagem). Por fim, como finalidade, 0 atendimento das necessidades de saúde do cliente por meio do cuidado de Enfermagem, que é consumido ao mesmo tempo em que é realizado $(7,8,15,20)$.

$\mathrm{Na} C \mathrm{ME}$, este processo configura-se de modo diferente, por caracterizar o seu objeto nos artigos e instrumentais a serem processados, o seu produto final nos artigos em condições seguras de uso e a sua finalidade no auxílio aos cuidados de Enfermagem e de saúde, realizado pel as unidades consumidoras. Sob este ponto de vista, podese dizer que a CME promove um cuidado ao cliente de maneira indireta, por instrumentalizar o cuidado direto prestado por outros setores ou serviços de saúde. Nesse sentido, as atividades desenvolvidas pelo enfermeiro da CM E estão incluídas no cuidado de Enfermagem e de saúde e pode ser considerado cuidado indireto, observado na organização do ambiente de saúde e na garantia da qualidade e segurança aos procedimentos de intervenção, por meio do processamento adequado de artigos ${ }^{(11,16,22)}$.

Embasado nestas informações, pensa-se que a CM E tem por objeto processar, armazenar e distribuir os artigos e instrumentais odonto-médico-hospitalares, utilizando para isso diversos instrumentos de trabalho (equipamentos, materiais, técnicas, normas, comunicação, conhecimentos científicos, educação em serviço, gerenciamento, etc). Por finalidade, tem o cuidado indireto por meio da disponibilização de artigos seguros que auxiliem e qualifiquem o cuidado direto prestado por outros setores (unidades consumidoras) para atender as necessidades de saúde dos clientes.

As práticas desenvolvidas pela Enfermagem na CM E , firmadas nos el ementos do seu processo de trabalho (objeto, finalidade, instrumentos e pessoas), necessitam de conhecimentos científicos e habilidades para serem efetivadas, que podem ser comparadas a "filmes" para serem assistidos e, em seguida, utilizados para auxiliar a direção de suas ações. Essas ações ficarão gravadas em sua história e podem ser reprisados e refletidos sempre que necessário. Supõe-se que para efetivar um processo de trabalho, em qualquer setor de saúde, é fundamental refletir e compreender as relações e os conceitos que envolvem sua prática, como uma atividade de reflexão importante ao entendimento do saber e fazer de uma profissão. 
3 MODELO CONCEITUAL NA CENTRAL DE MATERIAL E ESTERILIZAÇÃO: A ARTE DE DIRIGIRAAÇÃO

Conceitos e proposições são importantes ao conhecimento, à representação e à comunicação com a realidade e esta afirmação permite entender porque a Enfermagem está centrada na inter-relação de quatro conceitos (ser humano/pessoa, ambiente/sociedade, saúde/ doença e enfermagem) que constituem 0 seu metaparadigma. 0 inter-relacionamento dos conceitos forma uma base às ações da profissão e, à sua estrutura, dá-se 0 nome de marco conceitual, que pode ser comparado a uma câmera que capta, filma, registra e direciona novas imagens sobre situações ${ }^{(2,23)}$.

Por ser capaz de subsidiar uma prática, o marco conceitual deverá contemplar as particularidades da realidade na qual se deseja aplicá-lo ${ }^{(5)}$. A partir deste pensamento é que, neste artigo, apropriou-se do metaparadigma da Enfermagem para adaptá-lo ao processo de trabalho da CME e propor conceitos de ser humano, ambiente, saúde/doença e enfermagem.

0 conceito de ser humano envolve a concepção de criatura humana, de vida, de homem ou mul her e de corpo ${ }^{(4)}$. Esse ser é singular, integral e indivisível, formado por um conjunto de órgãos, tecidos e sentidos (corpo), de sentimentos e desejos (alma) e de pensamentos, criações, decisões e lembranças (mente), capaz de observar, aprender, decifrar, agir, transformar, criar, interagir, trabal har, ensinar. Pode ser considerado histórico e social, pois convive em ambientes, relaciona-se com outros seres, desenvolve e amplia potencialidades, troca experiências e sofre as transformações destes ambientes, ao mesmo tempo em que evolui com eles ${ }^{(24)}$.

Certamente, os verbos ser, estar e interagir são aplicáveis à vida do ser humano, pois suas características são, também, influências dos diversos ambientes que 0 cercam. Com esses, mantém relações de convivência e interpendência, o que I he confere a capacidade de crescer e desenvolver habilidades cognitivas e motoras e, com isso, torna-se dependente e integrante deste ambiente e do que acontece ao seu redor. Ao ser capaz de interagir com 0 meio e com outros seres, poder observar, aprender, criar e transformar de acordo com suas necessidades, e uma delas é a de sobrevivência, que foi estimuladora de uma ação exclusiva do ser humano: 0 uso de sua força física e intel ectual transformada em trabal ho. No trabalho, além de interagir com outros seres humanos, pode relaciona-se com objetos e materiais e, nestas relações, pode estar em diferentes posições, definidas conforme as atividades que desenvolve ou a profissão em que atua ${ }^{(23,8)}$.

Como o trabalhador da Enfermagem, desenvolve práticas em âmbito coletivo e cooperativo e para tanto, precisa ser qualificado para acompanhar os avanços e demandas dos serviços de saúde, necessita, portanto, aplicar suas habilidades cognitivas e motoras. Além disso, estabelece relações com outros trabal hadores (profissionais) de saúde e com seus clientes (que necessita de seus cuidados, juntamente com seus familiares). Todos estes são seres humanos diferentes, em posições diferentes, mas que interagem em um ambiente comum e que necessitam uns dos outros para alcançar seus objetivos. Desse modo, os seres humanos que envolvem e vinculam-se ao processo de trabalho da CME são: os trabalhadores de Enfermagem (enfermeiro, auxiliar e técnico de enfermagem), demais profissionais de saúde (das unidades consumidoras) e 0 cliente (a quem se destina à finalidade do trabalho desenvolvido no setor) ${ }^{(21,7,11)}$.

Baseado nas afirmações acima, propõe-se conceituar o ser humano na CM E como singular, integral eindivisível de corpo, alma e mente, capaz de observar, aprender, agir, interagir, socializar, ensinar e crescer. Tais características Ihe conferem a capacidade de criar e transformar a natureza e a sua realidade por meio do trabal ho, no qual estabelece relações dependentes com outros seres humanos e com objetos e materiais. Pode se apresentar como trabal hadores de Enfermagem (enfermeiro, técnicos e auxiliares de enfermagem envolvido nas atividades do setor), os quais mantêm relações dependentes com outros profissionais de saúde (que utilizam os produtos do setor para o atendimento direto ao cliente) e com o cliente (que utilizará os produtos produzidos pelo setor enquanto necessitar do atendimento).

Como trabalhador de Enfermagem, 0 ser humano necessita de ambientes para desenvolver sua prática. A pal avra ambiente significa "que está à roda ou em volta de pessoas ou coisas. 0 meio em que se vive; conjunto das particularidades de um meio social, natural ou histórico em que se situa a ação de uma narrativa" (4:43). Tal qual, a CM E constitui-se como um ambiente, pois está envol to por seres humanos que nele convivem e mantém relações por meio do trabalho e pode estar inserido em uma instituição de saúde, em um setor de saúde (centro cirúrgico) ou fora deles, como empresa independente de esterilização.

A CM E é definida como uma unidade funcional de apoio técnico, destinada a oferecer produtos (artigos odontomédico-hospitalares adequadamente processados) para outros setores ou instituições de saúde (unidades consumidoras), que realizam atendimento direto aos clientes e que responde, integralmente, pelos processos de recepção, preparo, esterilização, guarda e distribuição de artigos ${ }^{(25,16,18)}$. É visto como um setor vital à segurança e qualidade do cuidado de saúde prestado ao cliente ${ }^{(11,17)}$.

Esse ambiente pode afetar a vida do ser humano, por sua interdependência e convívio mútuo, e pode contribuir para sua saúde e doença, como espaço de relações e interações, composto de outros seres humanos (profissionais e clientes), objetos (materiais, equipamentos...), situações (atividades, diálogos, processos de trabalho) e outros ambientes (instituição de saúde, unidades consumidoras, setor de saúde) ${ }^{(10)}$. 
B aseado nas citações anteriores, conceitua-se a CM E como um ambiente de apoio técnico a outros setores ou instituições de saúde, possuidor de um processo de trabal ho particular, no qual os trabal hadores que o envolvem, mantêm relações com outros trabalhadores de saúde, com seus clientes, com materiais, equipamentos e com outros ambientes. Responsabiliza-se por receber, preparar, acondicionar, esterilizar, guardar e distribuir artigos odontomédico-hospital ares às unidades consumidoras que prestam atendimento direto ao cliente e, por isso, compreende-se que pode influenciar o processo saúde-doença de modo positivo ou negativo, pela qualidade e segurança dos artigos que fornecerá ao atendimento de saúde.

A o falar sobre o processo saúde-doença, pensa-se ser importante tratar o significado de cada uma das palavras que o compõe para, depois, conceituar o seu conjunto. Um processo pode ser entendido como um método, um sistema e ainda: "seqüência contínua de fatos que apresentam certa unidade, ou que se reproduzem com certa regularidade: andamento, desenvolvimento" (4:67-9). 0 termo saúde é conceituado como o estado em que se está normal ou um estado de equilíbrio habitual do organismo, enquanto a doença significa uma al teração no equilíbrio ou na saúde, um mal ou um conjunto de distúrbios orgânicos. Portanto, o processo saúde-doença pode ser compreendido como um sistema de ações em andamento que caracterizam, respectivamente, um estado de equilíbrio ou desequilíbrio do organismo (4).

A saúde pode ainda ser definida como um estado dinâmico de bem-estar físico, mental e social. Não pode ser definida apenas como uma ausência de doença (26). É uma condição básica à qualidade de vida, enquanto a doença representa uma ameaça à segurança; pode passar desapercebida e muda, mas a partir do momento que 0 organismo quebra o silêncio por meio da dor, torna-se consciente e a doença passa a exigir auxílio (27).

0 processo saúde-doença faz parte do ser humano e, ao relacionar-se com o meio ambiente, sua saúde também se relaciona e nesta relação pode encontrar outros seres vivos ${ }^{(28)}$ como, por exemplo, os microorganismos patogênicos e não-patogênicos, que compõem a biosfera terrestre. Neste ambiente comum, ambos vivem de relacionamentos e de trocas, que podem ser harmônicas (oportunismo) ou não (parasitismo), sendo que no parasitismo, um microorganismo vive às custas de outro e provoca reações no organismo maior, ou seja, ao hospedeiro, 0 que resulta em um conjunto de reações denominado, clinicamente, de infecção (13).

U ma infecção pode ser entendida como o resultado de danos causados por uma invasão, multiplicação ou ação de produtos tóxicos de agentes infecciosos no hospedeiro, que possibilita resposta imunológica manifestada em sinais e sintomas que caracterizam a doença infecciosa ${ }^{(11,13,17)}$. Elas representam um desequilíbrio na relação microorganismos/ hospedeiro, manifestado por reações em um organismo humano exposto a riscos, e que pode ser transmitido para outros seres. Por ser uma doença transmissível, possui "elos" que formam uma cadeia epidemiológica composta de agente infeccioso, reservatório (lugar onde o agente infeccioso vive e se multiplica), fonte (pessoa, animal, objeto ou substância que "carrega" o microorganismo), via de eliminação, transmissão (movimento do microorganismo da fonte ou reservatório para o hospedei ro: gotículas, ar, vetores e objeto ou material), penetração e hospedeiro suscetível (animal ou homem que entra em contato com o microorganismo) ${ }^{(13) .}$

A cadeia epidemiológica da infecção pode ocorrer em qual quer ambiente, mas se ocorrer ou se relacionar às ações de uma instituição de saúde, é chamada de Infecção Hospitalar, definida pela Portaria № 2.616 de 12 de maio de 1998 do Ministério da Saúde como aquela adquirida após a admissão do paciente ou manifestada durante ou após alta, se relacionada a procedimentos hospitalares ${ }^{(10)}$. Um exemplo desta relação é o procedimento cirúrgico, no qual o ser humano (cliente, trabal hador de Enfermagem ou de saúde) pode estar exposto a riscos e um deles éo de adquirir uma infecção (29).

0 risco de aquisição de infecção hospitalar pode estar relacionado ao trabal ho da CM E por meio do contato do cliente, do trabal hador de Enfermagem ou de saúde, com uma carga de microorganismos contida nos artigos odontomédico-hospitalares processados inadequadamente no setor. Porém, para que este contato ocorra, deve haver uma susceptibilidade do ser humano, advinda de um comprometimento imunitário, de uma exposição a procedimentos diagnósticos e terapêuticos e, ainda, pelo contato direto com tais artigos $(22,11)$.

A partir destas considerações, o processo de saúdedoença na CM E pode ser conceituado da seguinte maneira: a infecção (doença) corresponde a um desvio ou desequilíbrio do estado normal de saúde do ser humano, que pode ocorrer pela transmissão indireta de um agente infeccioso (microorganismo) a um hospedeiro suscetível (trabalhadores ou clientes) por meio de artigos odontomédico-hospitalares processados inadequadamente na CM E. Esse conjunto de fatores coloca em risco a saúde do cliente, do trabal hador de Enfermagem e do trabalhador de saúde que poderão manipular ou entrar em contato com estes artigos.

Sob esse ponto de vista, a equipe de Enfermagem da CME deve preocupar-se com sua condição de coresponsável pelo processo de saúde/doença dos clientes que procuram as instituições de saúde, pois, se apropriar de parte do cuidado de saúde (cuidado indireto), deverá articular arte e ciência no intuito de auxiliar e atender, com segurança e qualidade, as necessidades dos seus clientes.

Como ciência, a Enfermagem reúne conhecimentos organizados e, como arte, utiliza habilidade, sensibilidade, criatividade, articuladas à sua prática. Suas ações devem ser direcionadas para evitar danos, esclarecer riscos e benefícios, objetivando proporcionar melhores condições 
para o ser humano ter uma vida saudável. Isso poderá ser conseguido na utilização de estratégias para prevenir, manter e recuperar a saúde juntamente com a mobilização do ambiente e recursos que 0 envolvem ${ }^{(10)}$. A Enfermagem também pode ser considerada profissão, disciplina, ciência, arte, um conjunto de ser, estar, pensar, fazer que tem respal do legal e é exercida por uma equipe de enfermeiros, técnicos e auxiliares ${ }^{(30)}$

A Enfermagem utiliza saberes de outras ciências e delas realiza uma síntese para atender as suas necessidades específicas e atingir sua finalidade, que está no auxílio da promoção, prevenção e recuperação do indivíduo por meio do cuidado ${ }^{(20)}$. A lém disso, pode ser considerada uma prática social, pois responde às exi gências das práticas econômicas, políticas, ideológicas e sociais da organização produtiva em que está incluída e por inserir-se nos serviços de saúde e produzir práticas influenciadas por determinações deste setor produz ${ }^{(7,9)}$.

Desse modo, compreende-se o conceito de Enfermagem na CM E como uma profissão inserida em um contexto econômico, político e social que determina suas práticas de atuação e condi ciona seus processos de trabal ho que se compõe de objeto (cuidado de Enfermagem ao cliente), de finalidades (atendimento das necessidades dos indivíduos) e de instrumentos (que podem ser técnicas, processo de enfermagem, materiais, conhecimentos, pesquisa, etc). Utiliza arte e ciência que subsidiam seus saberes e práticas, constituindo-se numa maneira de ser, fazer, pensar, criar e transformar este ambiente onde atua e de interagir (cuidar, dialogar, agir e transformar) com os seres humanos. A presenta respaldo legal e mantém um exercício profissional que determina sua composição em enfermeiros, auxiliares e técnicos de enfermagem, como profissionais habilitados e capacitados à atuação.

Refletir sobre os conceitos que envolvem 0 metaparadigma da Enfermagem (ser humano, ambiente, Enfermagem e processo saúde-doença) e suas inter-relações ao processo de trabal ho da CME, auxilia a compreender as ações desenvolvidas neste setor. Os conceitos e as proposições que envolvem a CME são fundamentais ao entendimento do trabalho desenvolvido e cabe aos profissionais que nele atuam, compreender, refletir e propor novos caminhos e outras realidades utilizando, para isso, novas "câmeras" (conhecimentos, reflexões, ações) para que outras filmagens (model os, ações, saberes, práticas) possam acontecer.

\section{CONSIDERAÇÕES FINAIS}

Pensar a respeito de um marco conceitual para subsidiar o processo de trabalho da Enfermagem é uma atividade que necessita de reflexões que podem ser comparados ao retroceder de filmes que permitem rever imagens antigas, de diferentes momentos de sua história. Relembrar e refletir ações e saberes possibilitam a construção de novas imagens e novos filmes.

A Enfermagem construiu maneiras de ser, saber e fazer a profissão e, com isso, gravou novos filmes que foram subsidiados pelas ações de seu processo de trabalho, que vem sofrendo transformações ao longo do tempo. Tais transformações ocorrem por estar inserida em um contexto histórico, social e político dinâmico e pela necessidade de acompanhar as demandas de saúde, resolver problemas e ultrapassar obstáculos de sua prática e ensino. Especificamente na CME, as necessidades de auxiliar os procedimentos cirúrgicos e de reduzir os índices de infecções no pós-operatório fizeram necessárias reestruturações.

A partir disso, a Enfermagem construiu metodologias de trabalho que foram criadas como resultados das necessi dades da prática e, dentre elas, estão as suas teorias: instrumentos estruturados (compostos de elementos operacionais) que subsidiam ações e que devem ajustar-se as diferentes realidades. Dentro desta estrutura, estão os conceitos e as proposições, sendo que os primeiros representam abstrações e imagens de um fenômeno, e os segundos, deduções, propostas que, ao serem somados, formam o marco ou modelo conceitual de uma disciplina. 0 marco conceitual da Enfermagem se configura na interrel ação de conceitos (ser humano, ambiente, processo saúdedoença e Enfermagem) que formam o seu metaparadigma.

Nesse sentido, retrata-se a importância de refletir conceitos e proposições de uma disciplina, como instrumentos que direcionam os saberes e fazeres de uma profissão e que podem ser adaptados a diferentes realidades de sua prática. Por isso, jul ga-se que compreender o marco conceitual que envolve o processo de trabalho da Enfermagem na Central de $M$ aterial e Esterilização, é fundamental aos profissionais que desempenham atividades neste setor.

Para tanto, a leitura de vários autores que abordam as teorias de Enfermagem, o marco conceitual, o processo de trabalho e a Central de $M$ aterial e Esterilização possi bilitaram a compreensão dos conceitos que envolvem o seu metaparadigma nesse setor específico, o qual apresenta particularidades e se diferencia de outros setores da instituição de saúde.

As reflexões possibilitaram a compreensão dos conceitos de ser humano, de ambiente, do processo saúdedoença e de Enfermagem no processo de trabalho da CME, além do entendimento de que a sua inter-relação é importante e indispensável. A ssim, este artigo é findo com o intuito de contribuir para novas reflexões sobre o marco conceitual do processo de trabalho da Enfermagem na Central de M aterial e Esterilização, bem como para qualquer outro setor, como uma proposta a um fazer reflexivo e um estímulo para que os enfermeiros possam se perguntar:

[...] que Enfermagem é esta que estou desenvolvendo? Quem é o ser humano que estou assistindo? 0 que é o processo saú- 
de-doença a que o ser humano está exposto? E o meio ambiente, o que é? (31:12).

ABSTRACT: The Center of $M$ aterial and Sterilization (CMS) is a sector of the health service which has specific knowledge and performs specific practice to its working process and can bring about some thinking through the study of the nursing theories, their concepts (perceptions, definitions) and propositions (deductions, proposals) that may configure a conceptual landmark. This theoretical reflection aims to understand the concepts that involve the nursing work process at the CMS. A fter the authors' apprehension and discussion of the concepts which entail the nursing metaparadigm, that is, human being, environment, heal th-illness process and nursing, they were deemed to be adaptable to the CMS and be transformed into a tool to understand the center importance and to subsidize the nursing practice in this area.

KEY WORDS: Working process, Center of M aterial and Sterilization, concepts, propositions, nursing.

RESUMEN: La Central de M aterial y Esterilización (CM E) es un sector de servicios de salud que posee saberes y prácticas específicos a su proceso de trabajo pasibles de reflexiones que pueden ser realizadas por medio del estudio de las teorías de enfermería, de sus conceptos (percepciones, definiciones) y proposiciones (deducciones, propuestas) que, juntos, forman el mojón conceptual. Esta reflexión teórica tiene por objetivos comprender los conceptos que involucran el proceso de trabajo de la enfermería en la CM E y proponer un mojón conceptual para este campo, basado en los conceptos que forman el metaparadigma de la Enfermería: ser humano, ambiente, proceso salud/ enfermedad y enfermería. Tras la apropiación, discusión y propuesta de los conceptos, se percibió que éstos pueden ser adaptados a la práctica de la CME y volverse una "herramienta" para comprender la importancia de su trabajo y subsidiar la práctica de la enfermería en el campo.

PALABRAS CLAVE: Proceso de Trabajo; Central de $M$ aterial y Esterilización; Conceptos, Proposiciones, Enfermería.

\section{REFERÊNCIAS}

1. Meleis AI. Nursing theory: an elusive mirage or a mirror of reality. Philadel phia J B. Lippincott C 0., 1985. Theoretical nursing development \& progress; p.169-194. Trad. de Eloita Pereira Neves. Florianópolis: UFSC; 1985

2. Leopardi M T. Estudo de teorias. Florianópolis: Papa-livros; 1999. Teorias em enfermagem: instrumentos para a prática; p. $28-57$

3. King IM. Concepts: essential elements of theories. Nursing science quarterly, 1988; 1(1): 22-5.

4. Houaiss A . Pequeno dicionário enciclopédico K oogan Larousse. Rio de Janeiro: Larousse do Brasil; 1980.

5. Carraro TE. Sobre teorias e marco conceitual: sua influência na metodologia da assistência. In: Westphalen MEA, Carraro TE. $M$ etodologia para a assistência de enfermagem: teorizações, modelos e subsídios para a prática. Goiânia: A B; 2001. p.29-38

6. Marx K. O capital: crítica da economia política. 11. ed. São Paulo: A bril Cultural; 1987.

7. Capella BB, Leopardi MT. U ma abordagem sócio-humanística para um "modo de fazer" o trabalho da enfermagem. [dissertação]. Florianópolis: Setor de Ciências da Saúde da Universidade Federal de Santa Catarina; 1996.

8. Leopardi MT, Kirchhof AL, Capella BB, Pires DP, Faria EM, Ramos FRS et al. $O$ processo de trabalho em saúde: organização e subjetividade. Florianópolis: Papa-livros; 1999.

9. Kirchhof A LC. $O$ trabalho da enfermagem: análise e perspectivas. Rev Bras Enferm, 2003; 56(6): 669-73.

10. Carraro TE. Enfermagem e assistência: resgatando Florence Nightingale. Goiânia: A B; 1997.

11. Lacerda RA. Controle de infecção em centro cirúrgico: fatos, mitos e controvérsias. São Paulo: A theneu; 2003.

12. Thorwald J 0 século dos cirurgiões. Curitiba: Hemus; 2002.

13. Fernandes AT. Infecção hospitalar e suas interfaces na área da saúde. São Paulo: A theneu; 2000.

14. Gordon R. A assustadora história da medicina. 6. ed. Rio de J aneiro: Ediouro; 1996.

15. Geovanini T, M oreira A, Schoeller SD, M achado WCA. História da enfermagem: versões e interpretações. Rio de J aneiro: Revinter; 2002.

16. Possari J F. Centro de material e esterilização: planejamento e gestão. São Paulo: látria; 2003.

17. M artins M A. M anual de infecção hospitalar: epidemiologia, prevenção e controle. 2. ed. Rio de J aneiro: M edsi; 2001.

18. SOBECC - Sociedade B rasileira de Enfermeiros de Centro Cirúrgico. Recuperação anestésica e centro de material e esterilização: práticas recomendadas. 3. ed. São Paulo: SOBECC; 2005.

19. M eier MJ. Tecnologia em enfermagem: desenvolvimento de um conceito. [tese]. Florianópolis: Setor de Ciências da Saúde da Universidade Federal de Santa Catarina; 2004.

20. A Imeida M CP, Rocha SM M . 0 trabalho de enfermagem. São Paulo: Cortez; 1997.

21. M atos E, Pires D. N ovas formas de organização do trabal ho e aplicação na enfermagem: possibilidades e limites. [dissertação]. Florianópolis: Setor de Ciências da Saúde da Universidade Federal de Santa Catarina; 2002.

22. Tonelli SR, Lacerda RA. R efletindo sobre o cuidar no centro de material e esterilização. Rev SOBECC 2005; 10 (1): 28-31.

23. G eorge JB. Teorias de enfermagem: os fundamentos à prática profissional. 4.ed. Porto A legre: A rtes M edicas Sul; 2000. 
24. Dilly CML, J esus M CP. Processo educativo em enfermagem. São Paulo: Robe Editorial; 1995.

25. B rasil. RDC n. 50 de 21 de fevereiro de 2002 da A gência Nacional de Vigilância Sanitária do M inistério da Saúde. Dispõe sobre o Regulamento Técnico para planejamento, programação, elaboração e avaliação de projetos físicos de estabelecimentos assistenciais de saúde. Diário oficial da República Federativa do Brasil, Brasília, 21 fev. 2002. Disponível em: http://www.anvisa.gov.br ( 12 dez. 2002).

26. Smeltzer SC, B are BG. B runner \& Suddarth: tratado de enfermagem médico-cirúrgica. 8. ed. Rio de J aneiro: Guanabara K oogan; 1998.

27. Gualda DMR, Bergamasco RB. Enfermagem, cultura e o processo saúde-doença. São Paulo: İ́cone; 2004.

28. Capra F. 0 ponto de mutação. São Paulo: Cultrix; 1982.

29. M inistério da Saúde (BR ). Portaria no 2.616 de 12 de maio de 1998. Dispõe sobre diretrizes e normas para controle de infecção hospitalar. Diário Oficial da República Federativa do Brasil, Brasília, 12 mai. 1998. Disponível em: http://www.anvisa.gov.br/legis/portarias/2616_98.htm (10 junh. 2001).

30 L acerda RL. Enfermagem: uma maneira própria de ser, estar, pensar e fazer. Rev Bras Enferm 1998; 51 (2): 207-16.

31 Carraro TE. Enfermagem: de sua essência aos modelos de assistência. In: Westphalen, M EA .; Carraro, TE. M etodologia para a assistência de enfermagem: teorizações, modelos e subsídios para a prática. Goiânia: AB; 2001. p.5-15.

ENDERECO DOSAUTORES:

Rua Walenty Golas, 370 Curitiba-PR 81200-520

samarschall@ bol.com.br 